Case Report

\title{
SURGICAL TREATMENT OF MENINGIOMA WITH VENTRAL AND VENTROLATERAL LOCALIZATION IN THE REGION OF THE FORAMEN MAGNUM
}

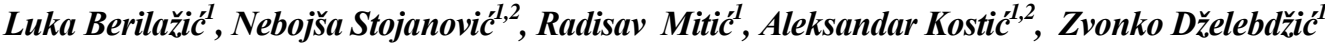 \\ ${ }^{1}$ Clinic for Neurosurgery, Clinical Center Niš, Serbia \\ ${ }^{2}$ University of Nišs, Faculty of Medicine, Nišs, Serbia
}

\begin{abstract}
Meningiomas localized in the ventral part of the foramen magnum always represent a surgical challenge. Analysis was performed on the surgical approach to meningiomas with ventral localization in the craniocervical region in 6 patients. Two posterolateral surgical approaches were used, depending on whether the tumor was at the level of the foramen magnum or it transited into the cervical spinal canal. In the case of a tumor at the level of the foramen magnum, posterolateral approach was used, with the suboccipital bone removal, and removal of part of the occipital condyles, with the resection of the atlas arch and mobilization of a.vertbralis. In tumors propagated in the spinal canal, the same resection of the occipital bone and occipital condyle was done, with the removal of the atlas and part of the atlantoaxial joint. Due to destabilization, occipitocervical fixation was performed in the second posterolateral approach. The posterolateral approach with the suboccipital removal of the bones and the atlas or, if necessary, with the resection of the occipital condyle or atlantoaxial joint, enables a good ventral separation of the tumor attachment and subsequent gradual complete removal. Fixation is required in the event of a removal of the atlantoaxial joint or removal of more than half of the occipital condyle. Posterolateral approach is an absolute indication in all cases of the ventral and ventrolateral localization of meningiomas in the area of the cervico-occipital junction, because it provides complete visualization of the tumor and allows for its safe removal.
\end{abstract}

Key words: posterolateral approach, occipitocervical junction, meningiomas of the foramen magnum.

\section{Introduction}

Meningiomas in the area of cervico-occipital junction are not a common pathology. Most often, they are localized in the ventral sections of the foramen magnum. The clinical picture that leads to their discovery is directly related to the compression of the brainstem and the lower group of the cranial nerves. The complex anatomical structure of the cervico-occipital junction is an aggravating factor in the planning of a surgical procedure. Therefore, good surgical planning is a prerequisite for a good post-operative outcome. Preservation of nervous and vascular structures is required during the complete removal of meningiomas, due to their benign nature. By using the posterolateral approach to the ventral part of the craniocervical junction, good visualization of neurovascular structures and tumor mass is enabled [1-3].

Correspondence to: Nebojša Stojanović Neurosurgery Clinic, Clinical Center Niš Zorana Đinđića 48, 18000 Niš, Serbia Phone: +38163109078

E-mail: nesamed59@ gmail.com Received November $22^{\text {nd }}, 2017$, accepted for publication December $11^{\text {th }}$, 2017

\section{Material and Methods}

A posterolateral surgical approach was analyzed in 6 patients who were operated on for the meningioma in the foramen magnum region. Surgery was performed on 4 women and 2 men. The clinical picture ranged from difficulty swallowing, difficulty walking, headache, buzzing in the ears, vomiting; it should be noted that 6 to 24 months elapsed from the onset of symptoms to diagnosis. The diagnosis included MSCT of the cranium, brain MRI, and PAN-angiography. The relationship of the tumor with the brainstem, nervous elements and vascular elements was analyzed preoperatively.

Two posterolateral approaches were used:

The first posterolateral approach accessed the tumors which were localized in the foramen magnum region, but did not extend below the level of the first cervical vertebra. The patient was placed in a sitting position with a slight flexion of the neck forwards and rotation of the head to the side from which the tumor process was accessed. After removing the muscle by a cut in the form of the reverse letter $\mathrm{L}$, the atlanto-occipital membrane was accessed and the atlas arch was completely dissected up to its juncture with the atlanto-occipital articulation. A.vertebralis was completely mobilized. Part of the occipital bone above the foramen mag- 
num on the side of the surgical access was removed; if necessary, part of the occipital condyle was also removed together with a part of the mastoid, and releasing of the sagittal sinus was done. The incision of the dura was done in the area of the atlanto-occipital membrane with an upward and downward expansion. After opening the dura, all neurovascular elements were completely visualized. The technique of precise microscopic separation of $\mathrm{n}$. accesorius and $\mathrm{n}$. hypoglossus from the tumor, with the mobilization of a.vertbralis [4] allows good visualization of the ventral part of the tumor and its attachment. For accessing the tumor, the windows between the accessory branches and the lower group of nerves are used. The tumor is always first separated from the attachment, preferably as a whole, and then removed piecemeal. It is essential that no traction of the nerves is made, although it is allowed to move them. There is always an arachnoid block [5] between the tumor and the brainstem, which enables secure preparation of the tumor and its separation from the brainstem (Fig. 1).

The second posterolateral approach was used to tumors that ran below the level of the first cervical vertebra. The approach is identical to the first case, but the expansion of decompression of the bones is performed to a greater or lesser extent, if necessary, with unilateral removal of the atlanto-axial (C1-C2) articulation. The principle of tumor removal is identical. Because of the destabilization of the articulations, the cervico-occipital stabilization is always performed (Fig. 2).
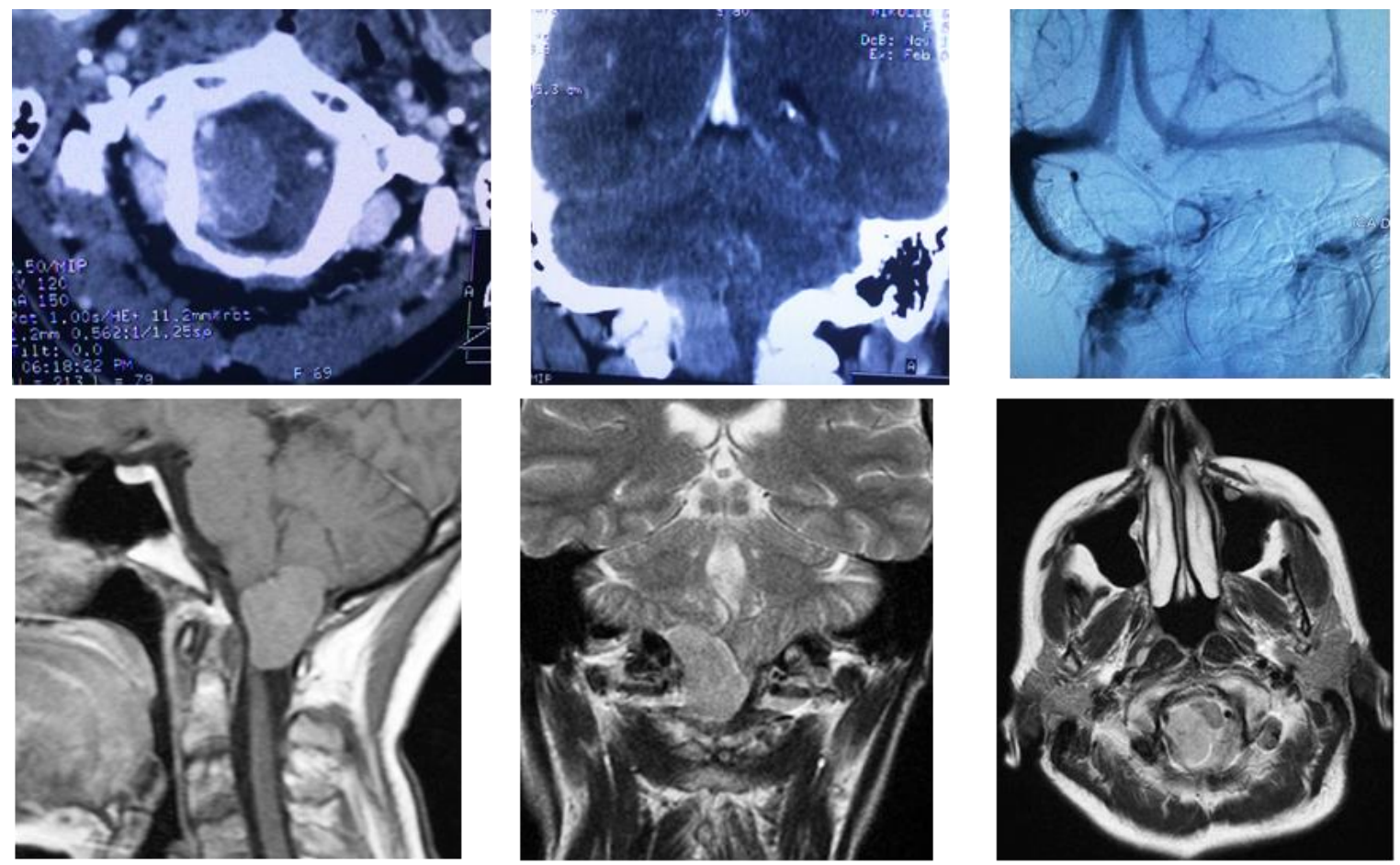

Preopertive MSCT, angiograph and NMR
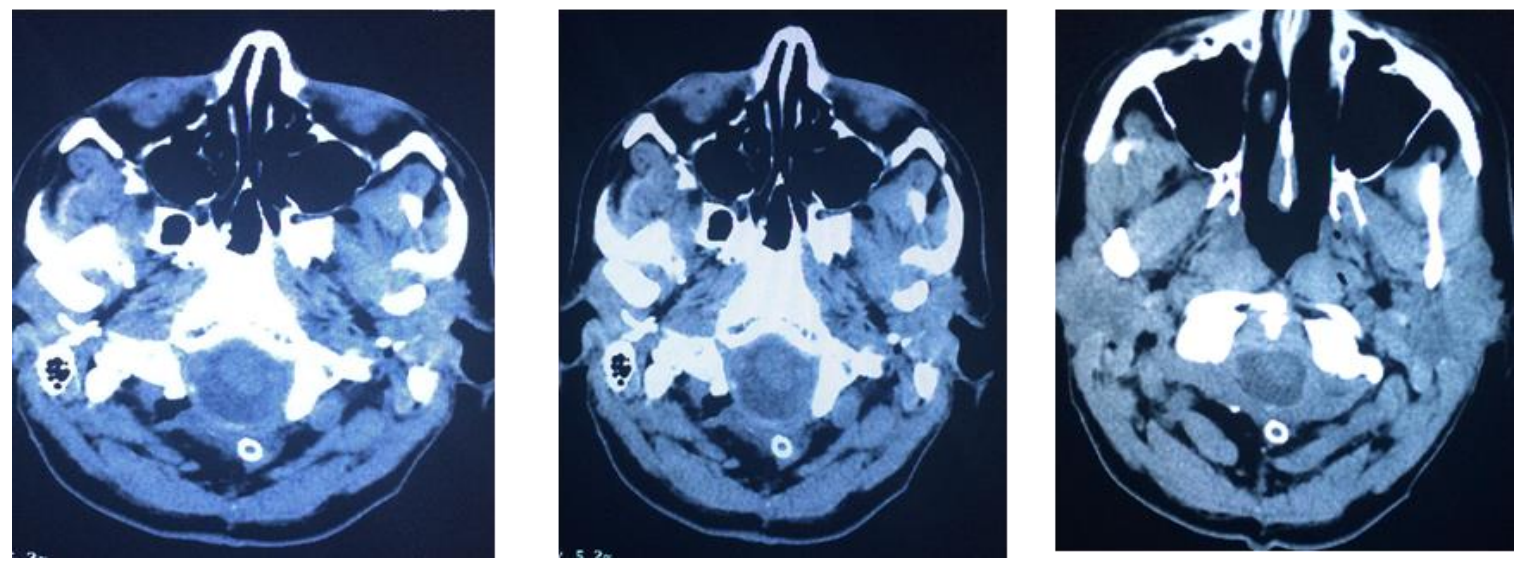

Postoperative MSCT / complete tumor removed

Fig. 1 Posterolateral approach with the complete removal of the lateral part of the atlas with the release of a. vertebralis and atlantooccipital joint 

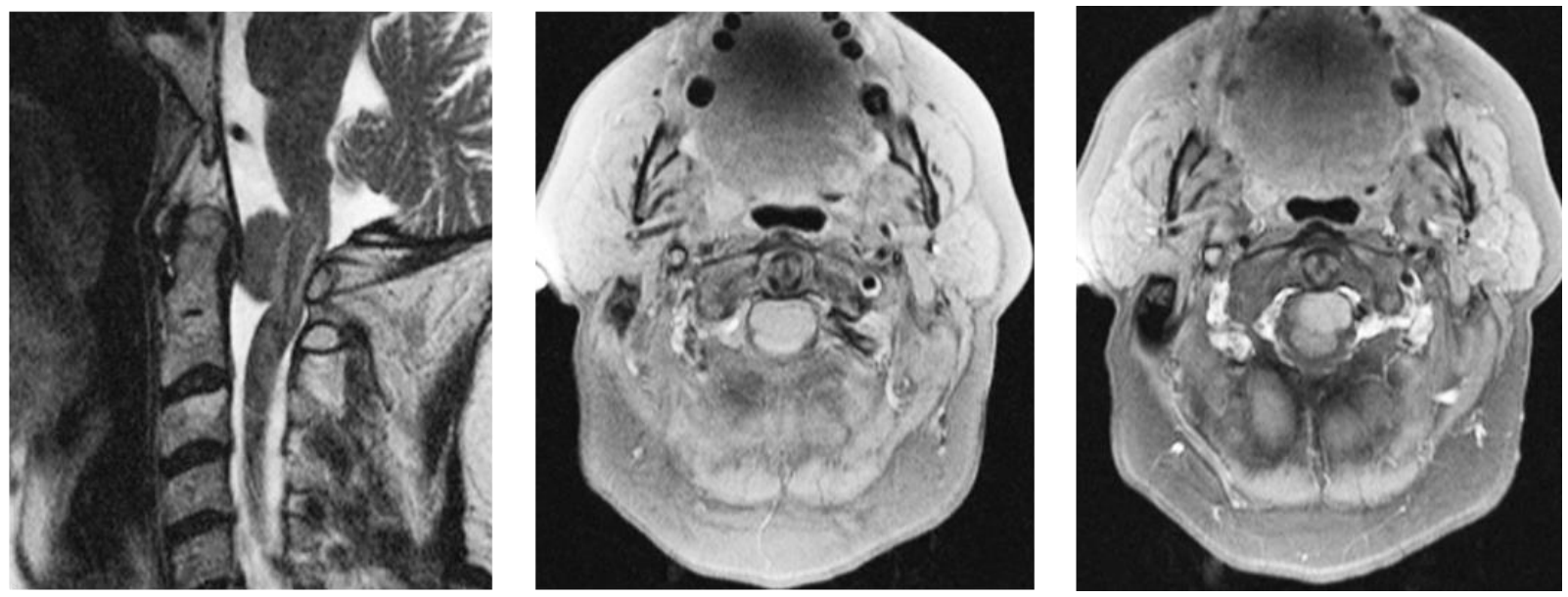

Preoperative NMR
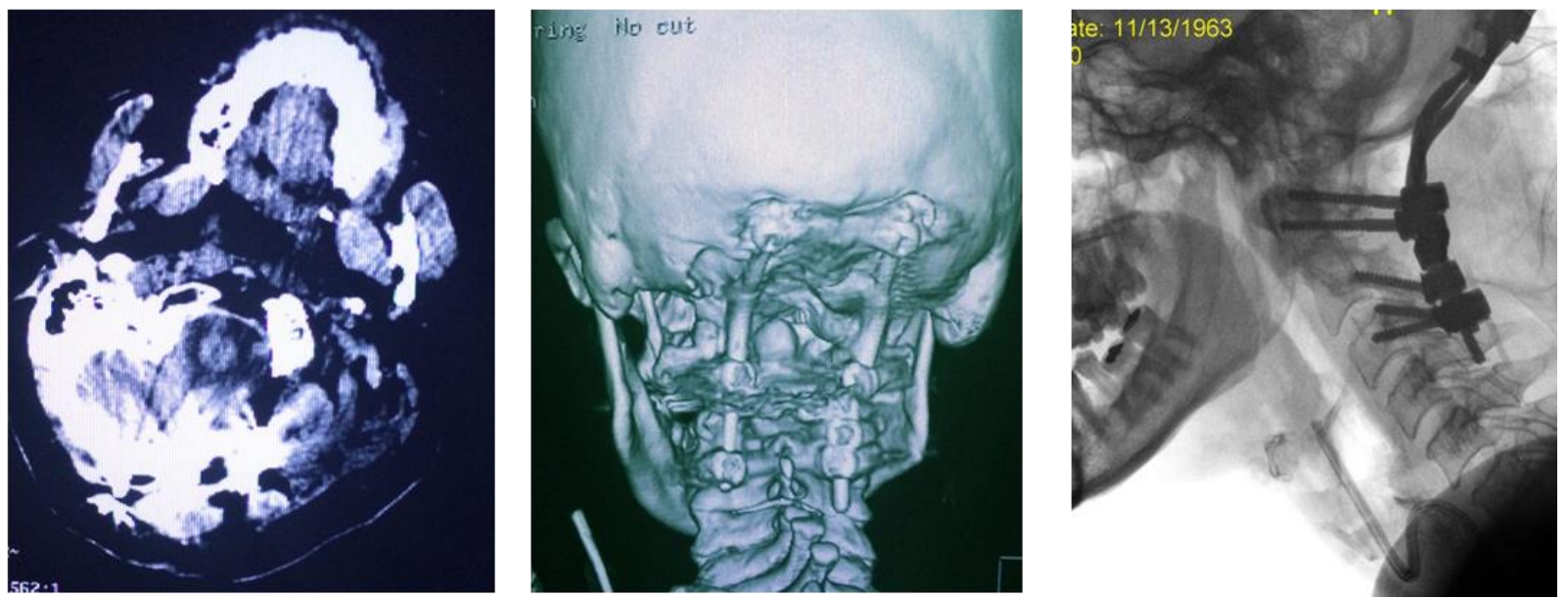

Postoperative MSCT/ complete tumor removed/ removing atalntoxial joint/ occipitocervical stabilization

Fig. 2 Posterolateral approach with the complete removal of atlas with the release of a.vertbralis, partial removal of atlantoaxial joint and cervicooccpital stabilization

\section{Results and Discussion}

After the resection of the bone and ligament structures, the posterolateral approach allows for good visualization of the tumor, its attachment and relationship with the neurovascular elements. Such an approach enabled complete removal of the tumor without damaging the surrounding structures, which is why the postoperative course was without neurological complications in all patients [6,7].

For smaller tumors, the posterolateral approach, with the resection of the atlas arch and mobilization of a. vertebralis, allows good visualization of the ventral part of the occipito-cervical junction and complete removal of the tumor $[8,9]$.

For larger tumor processes, the posterolateral approach must be expanded by a variable degree of resection of the occipital condyle and atlantoaxial articulation. This approach enables complete visualization of all neurovascular elements with the brainstem, but requires that cervico-occipital stabilization be performed upon ending the tumor surgery, due to destabilization in the articular systems. [10-12].

In 4 patients, the posterolateral approach was used with the atlas resection, which did not require stabilization. In all patients, the tumor was completely removed. One patient had a short-term problem with swallowing, but these symptoms disappearedafter a month. The other patients were without postoperative neurological problems. Residual neurological problems of the hemiparesis and muscular weakness type retreated over a period of several weeks to three months after surgery. There were no postoperative problems with moving the head in all directions.

In 2 patients with cervico-occipital fixation, limited neck mobility was present, but this did not significantly affect their daily life activities [13-15].

There were no neurological postoperative complications. It should be noted that bleeding was minimal during surgery, despite the fact that in some cases tumor vascularization was significant. 


\section{Conclusion}

The basic surgical principle is to reach a surgical substrate with minimal damage to the healthy structures and, most importantly, remove it without damaging the vital neurovascular structures. Within each surgical approach, the removal of the bones and ligament structures must be performed with respect to the size of the tumor being operated.

Surgical approaches for such tumor localization, whose implementation will increase the chance of major

\section{References}

1. Nikolas CB, Curtis AD, Robert FS, Volker KH. Surgery of the Craniovertebral Junction. $2^{\text {nd }}$ ed. 141-170.

2. Liu JK. Extreme lateral transcondylar approach for resection of ventrally based meningioma of the craniovertebral junction and upper cervical spine. Neurosurg Focus. 2012 Jul;33(Suppl 1):1

3. Jackler RK, Sim DW, Gutin PH, Pitts LH. Systematic approach to intradural tumors ventral to the brain stem. Am J Otol 1995; 16(1):39-51.

4. Park HH, Lee KS, Hong CK. Vertebral artery transposition via an extreme-lateral approach for anterior foramen magnum meningioma or craniocervical junction tumors. World Neurosurg 2016; 88:154-165.

5. Sohn S, Chung CK. Conventional posterior approach without far lateral approach for ventral foramen magnum meningiomas. J Korean Neurosurg Soc 2013; 54(5):373-378.

6. Refai D, Shin JH, Iannotti Ch, Benzel EC. Dorsal approaches to intradural extramedullary tumors of the craniovertebral junction. J Craniovertebr Junction Spine 2010; 1(1):49-54.

7. Bruneau M, George B. Foramen magnum meningiomas: detailed surgical approaches and technical aspects at Lariboisière Hospital and review of the literature. Neurosurg Rev 2008; 31(1):19-32.

8. George B, Lot G, Boissonnet H. Meningioma of the foramen magnum: a series of 40 cases. Surg Neurol 1997; 47(4):371-379.

9. Nanda A, Vincent DA, Vannemreddy PS, Baskaya MK, Chanda A. Far-lateral approach to intradural lesions of the foramen magnum without resection of the occipital condyle. $\mathbf{J}$ Neurosurg 2002; 96(2):302-309.

10. Lopez AJ, Scheer JK, Leibl KE, Smith ZA, Dlouhy BJ, Dahdaleh NS. Anatomy and biomechanics of the craniovertebral junction. Neurosurg Focus 2015; 38(4):E2.

11. Steinmetz MP, Mroz TE, Benzel EC. Craniovertebral junction: biomechanical considerations. Neurosurgery 2010; 66(3 Suppl): $7-12$. bleeding, infection, incomplete recovery, and the need for later reconstruction of the surgical entry, must be kept to a minimum or even eliminated [16-18].

The posterolateral approach to the ventral processes in the foramen magnum region absolutely allows good visualization of the ventral part of the cervico-occipital junction, good visualization of the relationship of the tumor with the neurovascular elements, and the complete removal of the tumor process [19-21].

12. Margalit NS, Lesser JB, Singer M, Sen C. Lateral approach to anterolateral tumors at the foramen magnum: factors determining surgical procedure. Neurosurgery 2005; 56(2 Suppl):324-336.

13. Zou J, Yuan C, Zhu R, Zhang Z, Jiang W, Yang H. Effect of occipitocervical fusion with screw-rod system for upper cervical spine tumor. BMC Surg 2014 May 18;14:30.

14. Desouza RM,Bull J, Casey AT. Rigid occipitocervical fixation: indications, outcomes, and complications in the modern era. $\mathrm{J}$ Neurosurg Spine 2013; 18(4):333-339.

15. Cheng BC1, Hafez MA, Cunningham B, Serhan H, Welch WC. Biomechanical evaluation of occipitocervicothoracic fusion: impact of partial or sequential fixation. Spine J 2008; 8(5):821-826.

16. Kratimenos GP, Crockard HA. The far lateral approach for ventrally placed foramen magnum and upper cervical spine tumours. Br J Neurosurg 1993; 7(2):129-140.

17. Chandra PS, Jaiswal AK, Mehta VS. Foramen magnum tumors: a series of 30 cases. Neurol India 2003; 51(2):193-196.

18. Sen CN, Sekhar LN. An extreme lateral approach to intradural lesions of the cervical spine and foramen magnum. Neurosurgery 1990; 27(2):197-204.

19. Komotar RJ, Zacharia BE, McGovern RA, Sisti MB, Bruce JN, D'Ambrosio AL. Approaches to anterior and anterolateral foramen magnum lesions: A critical review. J Craniovertebr Junction Spine 2010; 1(2):86-99.

20. Goel A, Desai K, Muzumdar D. Surgery on anterior foramen magnum meningiomas using a conventional posterior suboccipital approach: a report on an experience with 17 cases. Neurosurgery 2001; 49(1):102-106.

21. Zozulya YP, Slynko YI, Al-Qashqish II. Surgical treatment of ventral and ventrolateral intradural extramedullary tumors of craniovertebral and upper cervical localization. Asian J Neurosurg 2011; 6(1):18-25. 